\title{
A new species of the genus Thanatus (Araneae: Philodromidae) from Guangxi, China
}

\author{
Yingnan Wang ${ }^{1}$, Feng Zhang ${ }^{1 *} \&$ Shuwen Xing ${ }^{2}$ \\ ${ }^{\prime}$ College of Life Sciences, Hebei University, Baoding, Hebei 071002, P. R. China \\ ${ }^{2}$ Biological Department, Hanshan Normal University, Chaozhou, Guangdong 521041, P. R. China \\ *Corresponding author, E-mail:dudu06042001@163.com
}

\begin{abstract}
A new species of the genus Thanatus C. L. Koch 1837 is described from Guangxi Zhuang Autonomous Region, China under the name of Thanatus damingus.
\end{abstract}

Key words - spider, Thanatus, taxonomy, new species, China

\section{Introduction}

The genus Thanatus established by C. L. Koch in 1837 is the second largest genus in the family Philodromidae, with 97 species distributed around the world (Platnick 2012). The species of Thanatus are mainly distributed in Asia and Europe.

Up to the present, 13 species of Thanatus were described or recorded from China, as outlined below. Simon was the first arachnologist who recorded a Chinese Thanatus species, describing one new species, T. miniaceus Simon 1880, from Peking (Beijing) or in nearby Hebei Province. Philodromus mongolicus was described by Schenkel in 1936 and later transferred to Thanatus by Logunov in 1996. In fact, the most important contributor is Prof. Da-Xiang Song: he and his collaborators successively described and recorded many Thanatus species: T. vulgaris Simon 1870 from Xinjiang (Zhou \& Song 1985); T. albomaculatus Kulczyński 1908 [synonymized with T. coloradensis Keyserling 1880 by Logunov (1996)], T. coreanus Paik 1979, T. miniaceus, T. neimongol Urita \& Song 1987, T. nipponicus Yaginuma 1969, and T. vulgaris from the Inner Mongolia Autonomous Region (Urita \& Song 1987). $T$. hongkong Song, Zhu \& Hu was described from Hongkong, southern China in 1997. Other researchers have also been active: Hu \& Wu described T. xinjiangensis $\mathrm{Hu} \& \mathrm{Wu} 1989$ and Philodromus yiningensis $\mathrm{Hu} \& \mathrm{Wu} 1990$ [synonymized with T. oblongiusculus (Lucas 1846) by Logunov (1996)] from the Xinjiang Uygur Autonomous Region; Tang \& Wang (2008) described T. wuchuanensis and recoreded $T$. stepposus Logunov 1996 and T. arcticus Thorell 1872 from the Inner Mongolia Autonomous Region. In addition to the above 13 species, $T$. formicinus (Clerck 1757), type species of the genus, was recorded from China (Zhu \& Wang 1963, Zhang 1987, Chen \& Gao 1990 and Zhao 1993), however, it was listed as species inquirenda by Song \& Zhu (1997).
In summary, except $T$. hongkong distributed in Hongkong, southern China, most Thanatus species are distributed in north and northwest areas of China, especially the Xinjiang Uygur Autonomous Region and the Inner Mongolia Autonomous Region.

Recently, while examining the specimens collected from Daming Mountain, a National Natural Reserve, located in Guangxi Zhuang Autonomous Region, South China, we found a Thanatus species and recognized it as new to science. We will describe the species below.

\section{Material and methods}

All measurements are given in millimeters. Body length is the sum of lengths of carapace and abdomen, regardless of petiolus. Measurements of legs are given as follows: total length (femur + patella + tibia + metatarsus + tarsus). All specimens are preserved in $75 \%$ alcohol. They were examined and drawn under a Nikon SMZ1500 stereomicroscope equipped with an Abbe drawing device. Photographs were taken using the Leica M205A. Epigyne was cleared in warm solution of potassium hydroxide $(\mathrm{KOH})$, it was transferred to alcohol and temporarily mounted for drawing. All specimens examined in this study are deposited in the Museum of Hebei University (MHBU), Baoding, China.

The following abbreviations are used: ALE, anterior lateral eye; AME, anterior median eye; AME-ALE, distance between AME and ALE; AME-AME, distance between AMEs; MOA, median ocular area; PLE, posterior lateral eye; PME, posterior median eye; PME-PLE, distance between PME and PLE; PME-PME, distance between PMEs.

\section{Taxonomy}

Thanatus C. L. Koch 1837

Thanatus Simon 1895: 1064; Simon 1932: 885; Dondale \& 
Redner 1978: 107; Song \& Zhu 1997: 210; Song, Zhu \& Chen 1999: 477.

Type species: Araneus formicinus Clerck 1757.

Thanatus damingus sp. nov. (Figs. 1-12)

Type material. Holotype (ð)): Guangxi Zhuang Autonomous Region, Damingshan National Natural Reserve, Grand Canyon, 21 May 2011, Yingnan Wang leg. Paratypes: 1우, near the Damingshan hotel, 20 May 2011, Yingnan Wang leg.; 2우1 $0^{\star}$, Grand Canyon, 21 May 2011, Yingnan Wang leg.; 3 우, Huansha Falls, 23 May 2011, Yanqiu Peng leg.; 1 우조, 24 May 2011, Yuewang Temple, Yanqiu Peng leg.; 4 우2ð, Grand Canyon, 28 May 2011, Yingnan Wang leg.; 1 ㅇ, Grand Canyon, 29 May 2011, Yingnan Wang leg. All specimens were collected from China.

Etymology. The specific name is derived from the type locality.

Diagnosis. Among the congeners, this new species is very similar to T. hongkong Song, Zhu \& Wu 1997 in the structure of palpal organ, both have spherical bulb and hook-shaped embolus, but can be distinguished from the latter by: 1) male palpal tibia with a forked retrolateral tibial apophysis, while with a single triangular retrolateral tibial apophysis in the latter; 2) embolus longer than that of the latter.

Description. Male (holotype). Body length 3.67; cara-

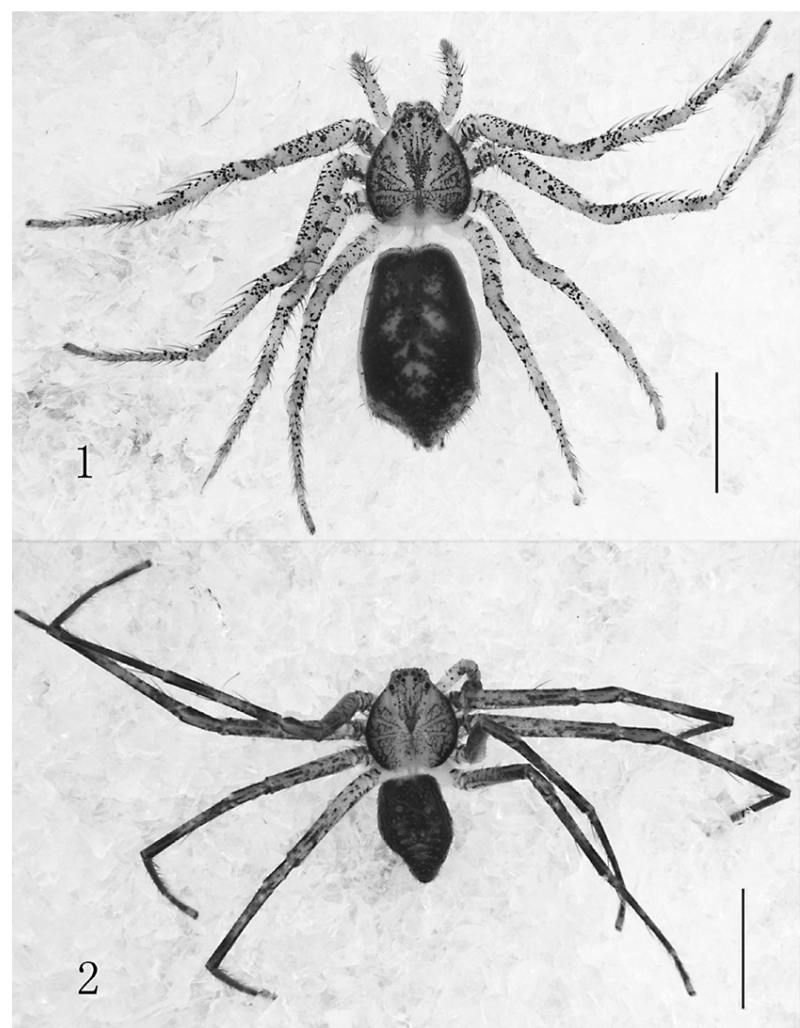

Figs. 1-2. Thanatus damingus sp. nov. 1. Female, dorsal view (paratype); 2. Male, dorsal view (holotype). Scales $=2 \mathrm{~mm}$.

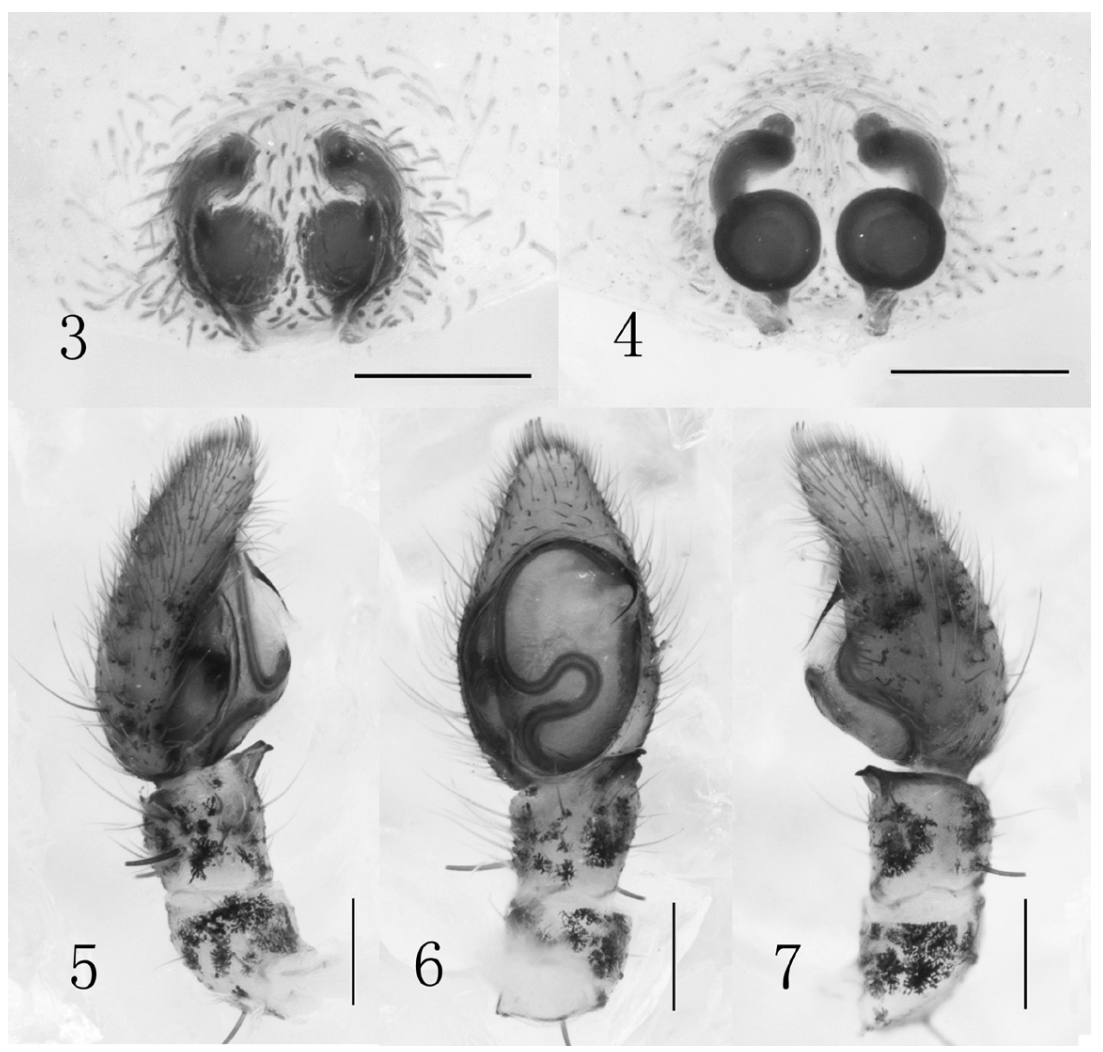

Figs. 3-7. Thanatus damingus sp. nov., female paratype (3-4) and male holotype (5-7). 3. Epigynum, ventral view; 4. Vulva, dorsal view; 5. Male left palp, prolateral view; 6. Same, ventral view; 7. Same, retrolateral view. Scales $=0.2 \mathrm{~mm}$. 

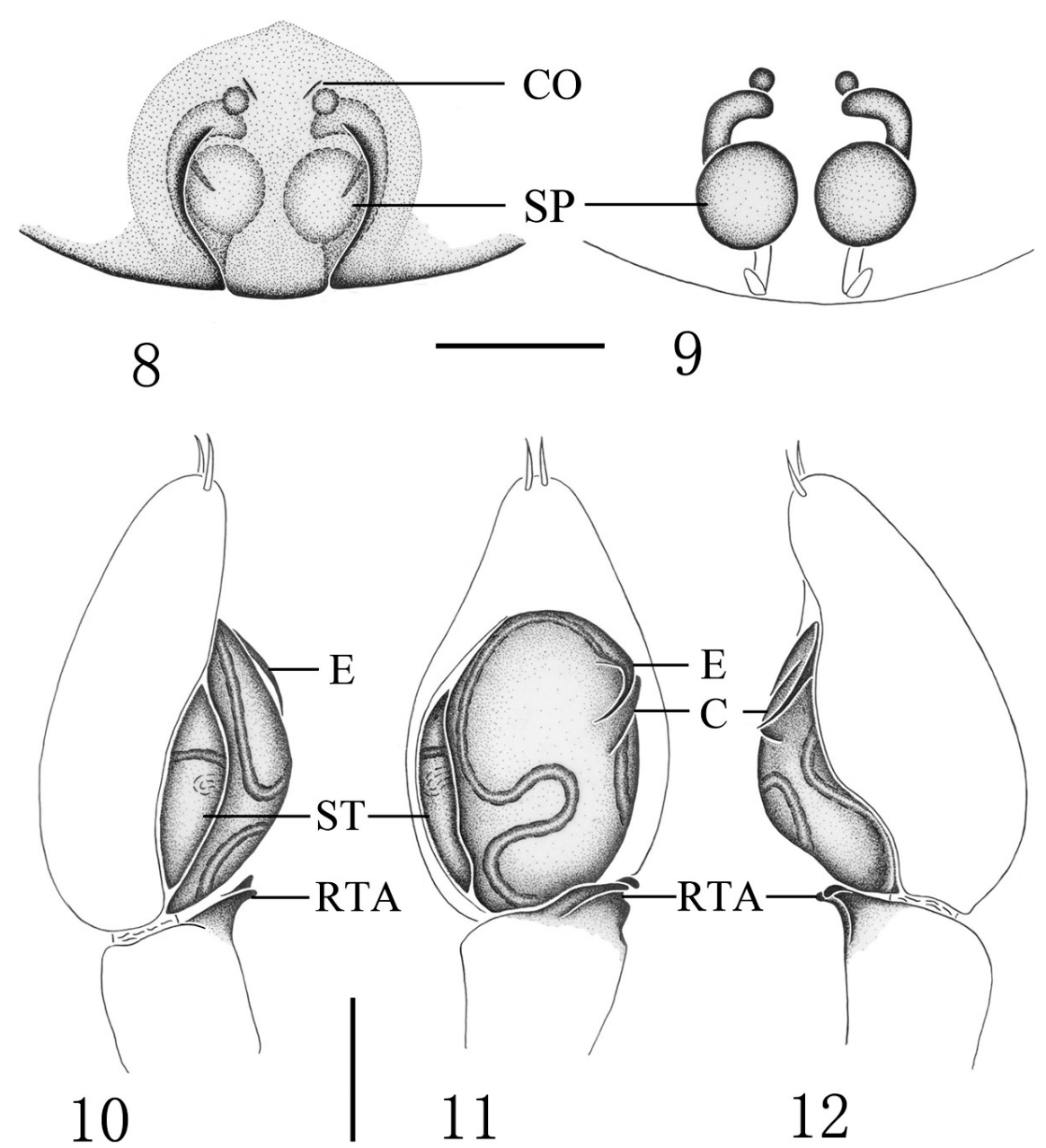

Figs. 8-12. Thanatus damingus sp. nov., female paratype (8-9) and male holotype (10-12). 8. Epigynum, ventral view; 9. Vulva, dorsal view; 10. Male left palp, prolateral view; 11. Same, ventral view; 12. Same, retrolateral view. Abbreviations: C, conductor; CO, copulatory opening; E, embolus; RTA, retrolateral tibial apophysis; SP, spermatheca; ST, subtegulum. Scales $=0.2 \mathrm{~mm}$.

pace length 1.73 , width 1.48 ; abdomen length 1.84 , width 1.22. Carapace (Fig. 2) yellowish brown with irregular black spots. Fovea longitudinal. Cervical groove and radial groove conspicuous. Cephalic region raised inconspicuously, with black thin setae. Both eye rows recurved, posterior eye row wider than anterior one; PLEs slightly projecting. Clypeal height 0.20. Eye diameters: AME 0.05, ALE 0.08, PME 0.05, PLE 0.10; eye interdistances: AMEAME 0.15, AME-ALE 0.05, PME-PME 0.13, PME-PLE 0.15 . MOA trapezoidal, wider than long (0.28: 0.15$)$, narrower in front than in back $(0.23: 0.28)$. Chelicerae yellowish brown, with two promarginal teeth (first the largest) and no retromarginal teeth. Labium yellowish brown, longer than wide $(0.30: 0.25)$. Endites yellow, edge with thick hairs. Sternum yellowish, longer than wide. Legs yellowish brown with black spots. Leg measurements: I 7.65 $(2.19+0.71+2.04+1.89+0.82), \quad$ II $9.08 \quad(2.60+0.77+$ $2.60+2.24+0.87), \quad$ III $6.89(2.09+0.71+1.79+1.53+$ $0.77)$, IV $6.88(2.14+0.66+1.68+1.63+0.77)$. Leg formula: 2134. Abdomen (Fig. 2) blackish brown, dorsum with two pairs of obvious muscle impressions.

Palpal tibia with a forked retrolateral tibial apophysis; bulb with subtegulum, tegulum with almost S-shaped sperm duct centrally, embolus hook-shaped from ventral view, with pointed tip (Figs. 6, 10).

Female (one paratype from Grand Canyon). Similar to male except for the following points. Body length 5.61; carapace length 2.00, width 1.73; abdomen length 3.37, width 2.09. Clypeal height 0.26 . Eye diameters: AME 0.05, ALE 0.08, PME 0.05, PLE 0.10; eye interdistances: AME-AME 0.18, AME-ALE 0.10, PME-PME 0.23, PMEPLE 0.25. MOA wider than long (0.85: 0.43), narrower in front than in back (0.50: 0.85). Chelicerae yellow. Labium wider than long $(0.33: 0.30)$. Legs yellow with lots of irregular black spots. Leg measurements: I $6.32(1.84+0.61$ $+1.73+1.48+0.66)$, II $7.44(2.19+0.82+2.04+1.68+$ $0.71)$, III $6.43(1.89+0.77+1.58+1.53+0.66)$, IV 6.33 $(2.00+0.71+1.53+1.43+0.66)$. Leg formula: 2341 . Abdomen (Fig. 1) relatively broad, blackish brown, with thin black setae; dorsum with five pairs of yellow patches and an inconspicuous blackish brown cardiac mark centrally; venter yellowish brown, with brown spots bilaterally.

Epigyne with curved lateral margins apart far away from each other, with a pair of seam-shaped copulatory openings 
anteriorly; copulatory ducts short and thick; spermathecae spherical (Figs. 3-4, 8-9).

Variation. Body lengths range from 4.18 to 6.02 in females (10 specimens) and from 3.32 to 3.62 in males (3 specimens).

Distribution. China (Guangxi).

\section{Acknowledgments}

We are grateful to Yanqiu Peng for collecting part of the specimen. Many thanks are also to Dr. Dongsheng Hu for his helpful comments for the first draft. This study was supported by the National Natural Science Foundation of China (No. 31071885, 30970325, 31093430), and partly by Science Fund for Young Scholars in Hebei University (No. 2010Q34).

\section{References}

Chen, X. E. \& Gao, J. C. 1990. The Sichuan farmland spiders in China. Sichuan Sci. Tech. Publ. House, Chengdu, 226 pp.

Clerck, C. 1757. Svenska spindlar, uti sina hufvud-slågter indelte samt under några och sextio särskildte arter beskrefne och med illuminerade figurer uplyste. Stockholmiae, $154 \mathrm{pp}$.

Dondale, C. D. \& Redner, J. H. 1978. The insects and arachnids of Canada, Part 5. The crab spiders of Canada and Alaska, Araneae: Philodromidae and Thomisidae. Research Branch, Agriculture Canada, Publ. 1663: 1-255.

Hu, J. L. \& Wu, W. G. 1989. Spiders from agricultural regions of Xinjiang Uygur Autonomous Region, China. Shandong Univ. Publ. House, Jinan, $435 \mathrm{pp}$.

Hu, J. L. \& Wu, W. G. 1990. Two new species of spiders of the genus Philodromus from Xinjiang Uygur Autonomous Region, China (Araneae, Philodromidae). J. Shadong Univ. 25: 110-115.

Logunov, D. V. 1996. A critical review of the spider genera Apollophanes O. P.-Cambridge, 1898 and Thanatus C. L. Koch, 1837 in North Asia (Araneae, Philodromidae). Rev. Arachnol. 11: 133-202.

Platnick, N. I. 2012. The world spider catalog, version 12.5, American
Museum of Natural History. Available from: http://research. amnh.org/entomology/spiders/catalog/index.html (accessed 3 April 2012)

Schenkel, E. 1936. Schwedisch-chinesische wissenschaftliche Expedition nach den nordwestlichen Provinzen Chinas, unter Leitung von Dr Sven Hedin und Prof. Su Ping-chang. Araneae gesammelt vom schwedischen Artz der Exped. Ark. Zool. 29(A1): $1-314$.

Simon, E. 1880. Etudes arachnologiques. 11e Mémoire. XVII. Arachnides recueilles aux environs de Pékin par M. V. Collin de Plancy. Ann. Soc. Ent. Fr. (5) 10: 97-128.

Simon, E. 1895. Histoire naturelle des araignees. Paris, 1: 761-1084.

Simon, E. 1932. Les arachnides de France. Tome VI. Synopsis générale et catalogue des espèces françaises de l'ordre des Araneae; 4e partie. Paris, 6: 773-978.

Song, D. X. \& Zhu, M. S. 1997. Fauna Sinica: Arachnida: Araneae: Thomisidae, Philodromidae. Science Press, Beijing, 259 pp.

Song, D. X., Zhu, M. S. \& Chen, J. 1999. The Spiders of China. Hebei Sci. Technol. Publ. House, Shijiazhuang, 640 pp.

Song, D. X., Zhu, M. S. \& Wu, K. Y. 1997. Some new species of the spiders from Hong Kong. Acta Arachnol. Sin, 6: 81-86.

Tang, G. M. \& Wang, J. J. 2008. One new species and two records of the genus Thanatus from Inner Mongolia, China (Araneae: Philodromidae). Acta Arachnol. Sin., 17: 76-80.

Urita \& Song, D. X. 1987. Notes on Inner Mongolian spiders of the family Philodromidae. J. Inner Mongolia Teacher's Univ. 1987(1): 28-37.

Zhang, W. S. 1987. Farm spiders from Hebei Province. Hebei Sci. Tech. Press, 299 pp.

Zhao, J. Z. 1993. Spiders in the Cotton Fields in China. Wuhan Publ. House, Wuhan, China, $552 \mathrm{pp}$.

Zhou, N. L. \& Song, D. X. 1985. Six new records of spiders from China. La Animala Mondo 2: 271-276.

Zhu, C. D. \& Wang, F. Z. 1963. Thomisidae of China, I. J. Jilin Med. Univ. 5: 471-488.

Received April 20, 2012 / Accepted July 14, 2012 